\title{
Preparation of Observation Base for Classical Surveys for Verification Purposes of Applying Modern Techniques for Measuring Displacement of Retaining Walls ${ }^{* *}$
}

\section{Introduction}

Landslides and landslips are the geological phenomena which are both important and difficult due to their tragic and widespread consequences for the population. The recent landslides which occurred in the southern Poland in 2010 after the long-term rainfall - e.g. in Milówka or Lanckorona, could serve as examples. Prevention of landslides is an important geotechnical issue.

Protecting slopes from sliding is problematic both due to a need to examine the structure of land and a reliable risk assessment of the landslide occurrence [9]. Due to the scale of the aforementioned phenomena, it is particularly important to properly protect slopes against the loss of their stability. This problem applies both to the natural and artificial slopes. One method of strengthening embankments and slopes is the construction of retaining walls [3].

Retaining walls are important building structures for the safety of people. According to the standard PN-B-03010:1983 [7], retaining walls are "structures able to sustain a stable state of native soil or of made ground overburden offset, or of other particulate materials, which can be characterized by geotechnical parameters $(\gamma-$ specific weight of the soil, $\Phi$ - angle of internal friction of the soil, $c$ - the consistency of the soil)". Therefore, it can be said that the task of retaining walls is to support the soil or other material which is behind them and to ensure its stability [1].

Building structures are subject to geotechnical categories which entails the selection of an appropriate method of calculation in designing a structure, as well as a scope of geotechnical identification [2].

* AGH University of Science and Technology, Faculty of Mining Surveying and Environmental Engineering Krakow, Poland

** This study was carried out with financial support from the Dean Project of the Faculty of Mining Surveying and Environmental Engineering (AGH University of Science and Technology) no. 15.11.150.203/13 
In accordance with the standard EN 1997-1:2004 [2], there are three geotechnical categories:

- the first one, including small and relatively simple structures;

- the second one, consisting of typical structures and foundations, which do not pose a particular risk, or situations where there are no difficult ground or load conditions;

- the third one, which can include the above structures if they are very large or unusual, or if they are exposed to extraordinary risk, or they are in unusual or exceptionally difficult ground or load conditions.

In order to ensure the safety and quality of building structures, the behavior of a structure during its construction and after its completion should, where necessary, be monitored. According to EN 1997-1:2004, the monitoring period after the construction has been completed, for objects that can adversely affect the surrounding areas, or the failure of which may pose a risk to life or property, should last longer than 10 years, or even for the whole period of the structure use. According to the aforementioned standard, in the case of the second geotechnical category, the assessment of structural behavior can be based on displacement surveys of selected points of the structure. However, in the case of the third geotechnical category, it is recommended that surveys of displacements were the basis for the assessment of a structure [2].

The shape and size of retaining structures, as well as their location often near busy roads, make their measurements using classical methods difficult and timeconsuming. Modern techniques such as laser scanning and ground-based radar interferometry allow us to make a relatively quick survey with high accuracy. The aim of this study is to verify the use of these surveying techniques by comparing the results of retaining structure measurements obtained from modern instruments with the results from classical precision surveying methods.

\section{Description of the Structure}

The subject of a survey was a set of retaining walls (Fig. 1) located at the national road. The sum of the wall height to be measured was about $20 \mathrm{~m}$.

The first part of the measured structure - wall 1 - was a wall of soil nails protected with monolithic facing of square-shaped reinforced concrete blocks with a side length of $1.5 \mathrm{~m}$ (Fig. 2). The length of the wall 1 was almost $200 \mathrm{~m}$ and the height reached about $10 \mathrm{~m}$. The whole wall 1 was included in the measurement.

The second part of the measured object - wall 2 - consisted of two types of structures (Fig. 2): a wall of reinforced soil (2.1) and a wall of soil nails protected in two ways: with monolithic facing of square-shaped reinforced concrete blocks with a side length of $1.5 \mathrm{~m} \mathrm{(2.2)} \mathrm{and} \mathrm{a} \mathrm{facing} \mathrm{with} \mathrm{a} \mathrm{flat} \mathrm{surface} \mathrm{(2.3)} \mathrm{allowing} \mathrm{further} \mathrm{con-}$ creting in the future. The current level of the road is a temporary one, and during the 
the planned reconstruction of the national road into an expressway it will be raised and it will cover the lower part of the wall 2, i.e. 2.3. Wall number 2 had a length of 2 and the maximum height of about $9 \mathrm{~m}$.

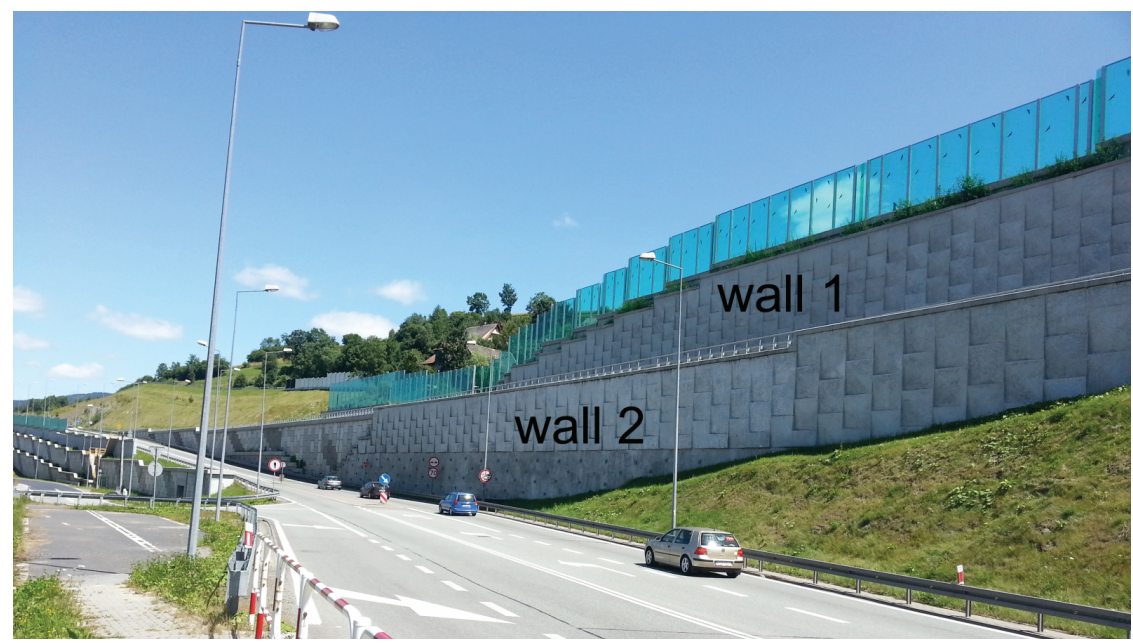

Fig. 1. The structure subject to the surveys

Different types of retaining structures can be distinguished in the walls. The survey covered the two largest walls with dominant retaining structures.
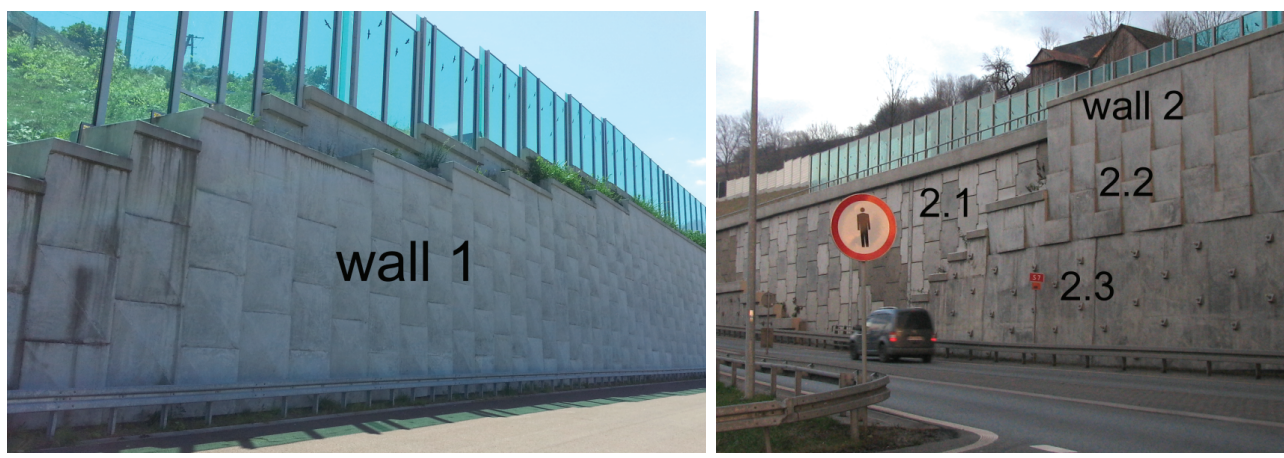

Fig. 2. Fragments of the retaining walls subject to the surveys

To strengthen the measured structure, modern and frequently used stabilization techniques were applied: soil nails and reinforced soil.

Soil nails, or passive ground anchors, work as a result of friction of the soil over the entire surface area. Recently, more and more commonly applied are TITAN self-drilled anchors [6]. This method of strengthening soil was used for the studied object, as in the case of [5]. 
The nailed structure consisted of three basic components [8]:

- the existing ground or rock material,

- the self-drilled TITAN injection nails,

- the nailed surface finish.

The effectiveness of nailing is affected by the efficiency of integrating nails with the soil. In the TITAN systems, the drilling is performed without protective pipes, and the injection is carried out from the very start of the drilling process, which allows for a deep penetration of the grout into the soil and an increase in the load capacity of a nail [8]. Figure 3 schematically presents the discussed soil nails.
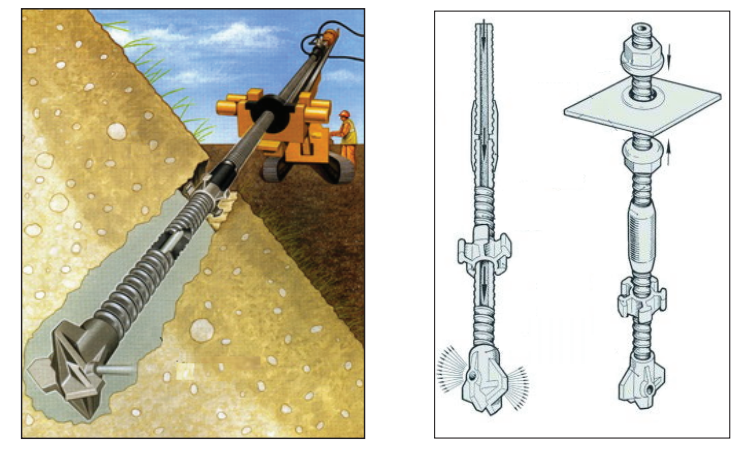

Fig. 3. The technique of strengthening soil with TITAN nails

Source: $[4,8]$

According to the standard PN-B-03010:1983 [7], a retaining wall of reinforced soil is a mass formed by a combination of soil and reinforcement layers carrying tensile forces. Steel, ribbed, galvanized reinforcing strips are placed inside the embankment (or backfill) at regular intervals. The embankment reinforced in such a way, through the compression of the soil, becomes a self-supporting structure. A classical reinforced soil has been presented in Figure 4. The finish of the entire reinforcement block is a lightweight facing of metal profiles or of precast concrete elements [6].

a)

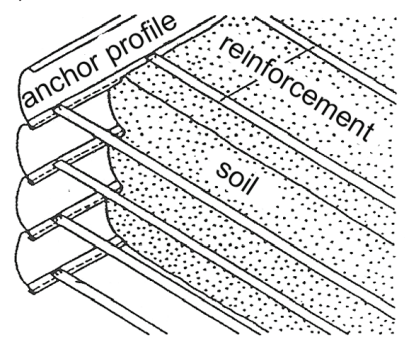

b)
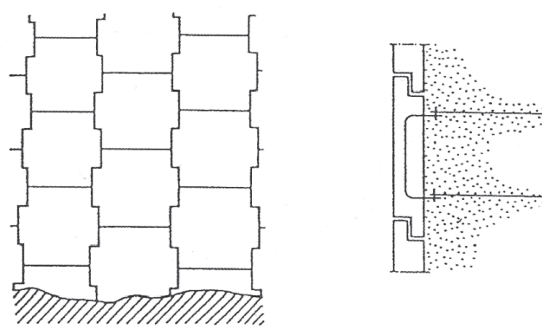

Fig. 4. The classical reinforced soil

Source: [6] 
Application of the retaining structures discussed above resulted from difficult ground conditions which excluded a possibility of direct foundation of a building structure. The discussed solutions resulting from similar field conditions have been presented in the literature [5].

\section{Control Network Project}

\subsection{Horizontal Network}

For the measurement purposes, the control network was fixed covering the test structure and its surroundings. A location sketch of a structure and its surroundings has been shown in Figure 5.

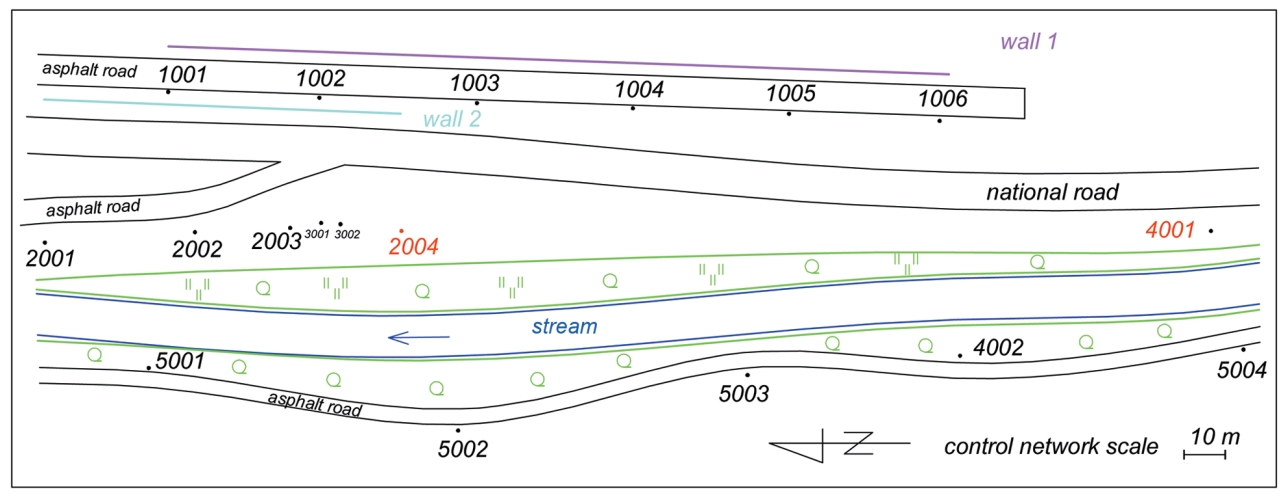

Fig. 5. Location of the control network with respect to retaining walls and surroundings

Retaining walls 1 and 2 are located in the immediate vicinity of a national road that runs near a creek. The relief, land development and shape of the retaining structures conditioned the location of control points.

Since a significant part of the control network points are located on the asphalt and concrete road finishing elements, their movement in time between consecutive measurement sessions is being assumed, due to the instability of these materials and their reaction to temperature, for example. Therefore, four points outside the structure (5001-5004) were fixed, representing a base of reference for the rest of the network. They are located on the bank of the creek opposite to the retaining wall and other control points, and they are within about 80 meters from the structure. They have been stabilized with reinforcing bars with drilled centers with a length of $1.3 \mathrm{~m}$ and a diameter of $10 \mathrm{~mm}$, driven vertically into the ground, flush with the ground level. In each subsequent measurement session, re-measurement of the control network would be carried out. Using a similarity transformation method, the mutual 
stability of the reference points and other control points would be checked, and the current coordinates of the control points in relation to the reference points would be determined.

The initial measurement of the control network was carried out using Leica TCA2003, whose angular accuracy is $m_{\alpha}=0.5^{\prime \prime}$, and the accuracy of the distancemeter $m_{d}=1 \mathrm{~mm}+1 \mathrm{ppm}$. The sketch of the control network after adjustment with the error ellipses is shown in Figure 6.

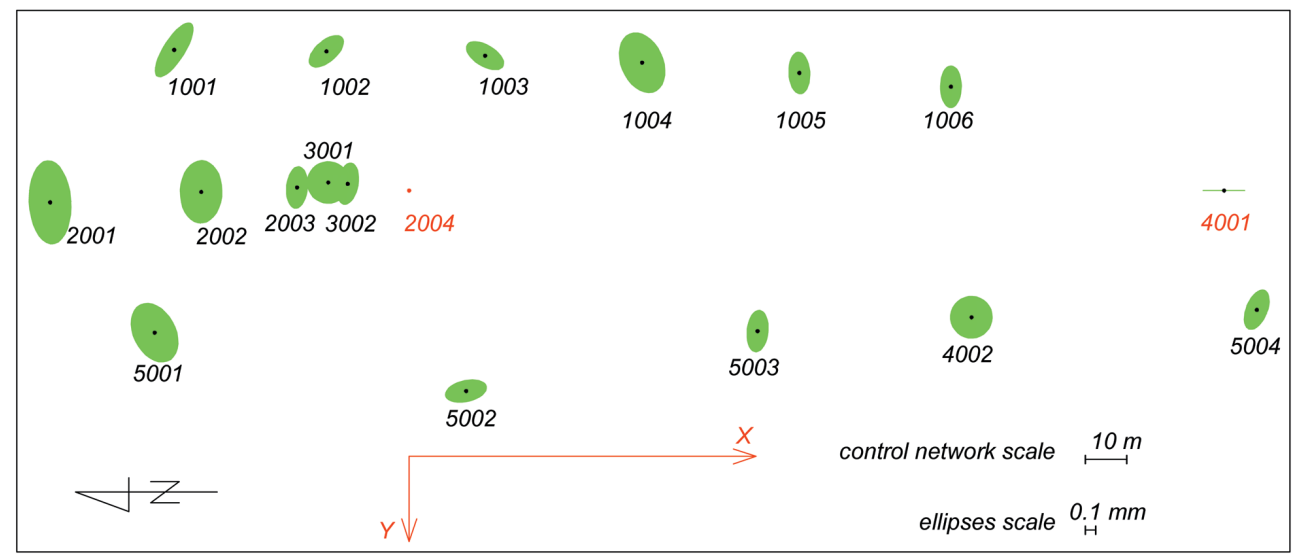

Fig. 6. Sketch of the measurement control network with error ellipses

The control network includes a total of 18 points and it covers an area of approximately a rectangle of $280 \times 80$ meters. The size of the control network results from the size and location of the retaining walls and their relative position. In addition, the position of the reference points is resulted from a limited aiming direction (bushes and shrubs) between them and the other control network points.

In the adjustment of the control network it was adopted as follows: a fixed point - point 2004, a fixed direction - direction 2004-4001. Thanks to high accuracy measurements and adequate planning of the control network surveying, the average error of a point position after alignment was $m_{p \text { avg }}=0.3 \mathrm{~mm}$, and the maximum error of a point position was $m_{p \max }=0.4 \mathrm{~mm}$ for the points 2001 and 5001 .

The angular intersection was selected as a measurement method, the results of which are to be the basis for comparison with the results of modern measurement techniques. It was considered to be the most accurate classical method of determining coordinates without the use of a distance-meter. Further, the control points would serve as a base for the angular intersection. Due to a short distance of the control points from the retaining walls, the intersection geometry is unfavorable. Therefore, for each of the walls several bases were created so that the intersection angles were not too acute. Points 1001-1006 are used for surveying the wall 1, points 2001-2002 - for the wall 2. Points 3001-3002 serve for the surveys 
using ground-based radar interferometry. Points 4001 and 4002 were lost positions which were aimed at strengthening the network during the surveys and adjustment. Points 5001-5004 are the reference points.

\subsection{The Leveling Network}

For the elevation control of the structure, precise leveling of the benchmarks established on the structure was carried out. On the wall 1, three benchmarks at the bottom of the wall were subject to surveying, and three benchmarks in the upper part of the wall, evenly distributed. On the wall 2, four benchmarks at the bottom were surveyed and four in the upper part, also evenly distributed.

Leveling of the benchmarks was performed using Leica DNA03 level, whose measurement accuracy using fiberglass staffs is $1.0 \mathrm{~mm} / \mathrm{km}$ of double-run leveling. The heights of the benchmarks on the structure were determined in relation to the benchmark established on the church, which was about $2 \mathrm{~km}$ away from the structure. Invar staffs ensuring the accuracy of $0.3 \mathrm{~mm} / \mathrm{km}$ of double-run leveling were used for reference surveying.

The heights of the benchmarks are also used to determine the height of the total station line of sight during the surveys of angular intersections, and ultimately to determine the height of the targets (controlled points) on the structure.

\section{Description of the Surveys}

\subsection{Classical Survey of the Wall 1}

For the purpose of surveying the wall 1, six points of the control network were fixed: 1001-1006, which made up 5 bases for the angular intersection. A total of 129 controlled points were established on the wall as a reflective tape (Figs 7, 8).

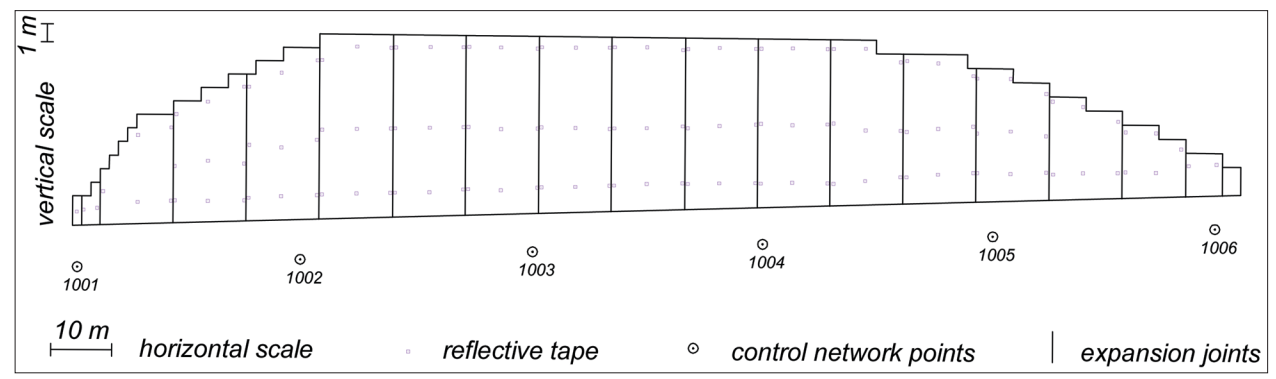

Fig. 7. Distribution of control network and controlled points on the wall 1

The wall is divided by expansion joints. The points were arranged so that in each block there were 9 points in 3 horizontal rows and in 3 vertical ones, covering the entire block. This did not apply to extreme blocks, which are smaller. 


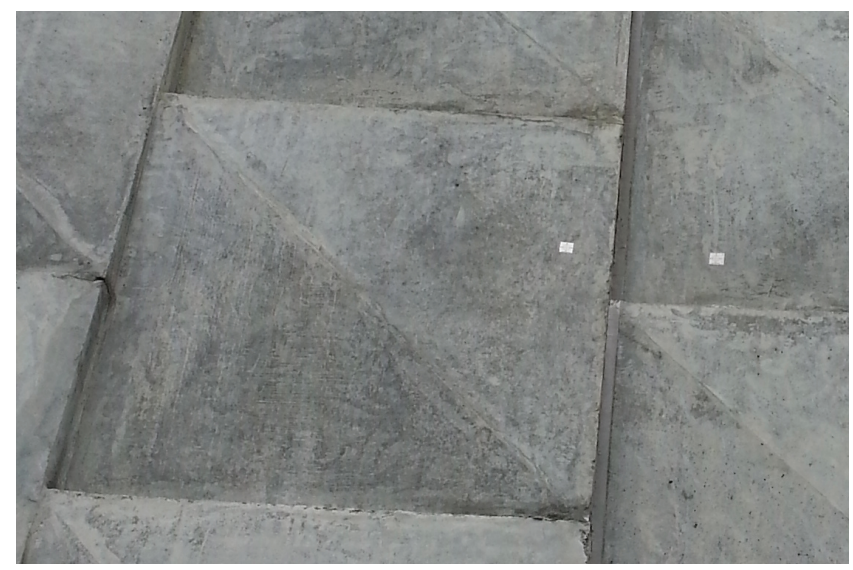

Fig. 8. Reflective tape targets on reinforced concrete facing on the opposite sides of the expansion joint

Determination of the coordinates of the controlled points was carried out by the angular intersection method using two precise total stations: Leica TC2002 and Leica TCA2003, the angular accuracy of which is $m_{\alpha}=0.5^{\prime \prime}$.

\subsection{Classical Survey of the Wall 2}

For the purpose of surveying the wall 2 using the angular intersection method, 2001-2004 control points were used. As in the case of the wall 1, the controlled points were marked with reflective tape. On the wall 2, a total of 55 controlled points were established. On the reinforced soil facing 15 points were marked. On the wall of soil nails 40 points were established, including 15 on the square-shaped monolithic reinforced concrete facing, and 25 on the flat surface facing. Figure 9 presents the distribution of the points on the wall 2. For measuring the intersections, the aforementioned high precision total stations were used.

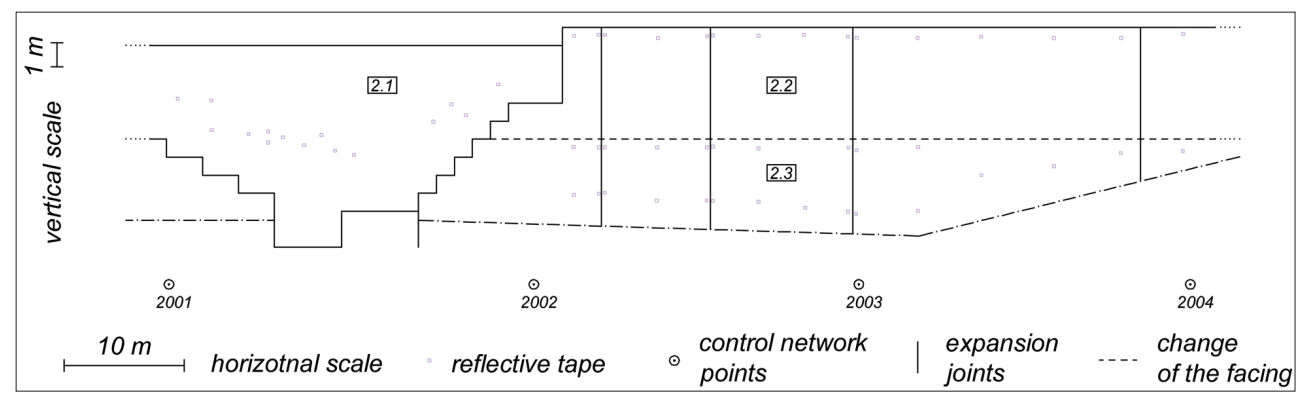

Fig. 9. Distribution of control network and controlled points on the wall 2 
On this part of the wall 2 which is reinforced with ground nails, the points were arranged regularly on the individual blocks divided by the expansion joints - as it was on the wall 1. In contrast, on the reinforced soil facing, one reflective tape was placed on each selected facing panel, as shown in Figure 10.

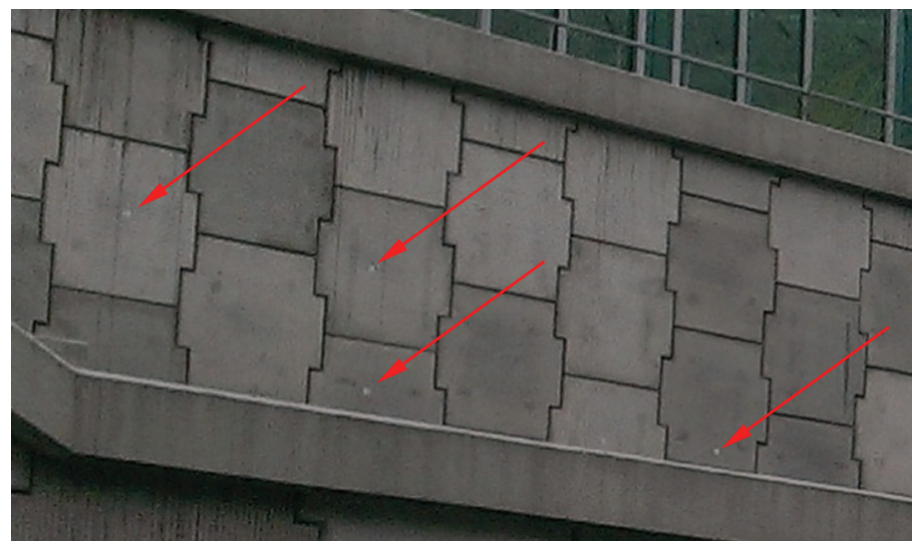

Fig. 10. The reflective tape on the reinforced soil facing

\section{Summary}

Surveying of large structures using classical methods is very time-consuming. Marking controlled points on a high structure requires the use of a lift or a high ladder. In addition, such surveys require stabilization and the measurement of an extensive control network and, as well as in the case above, the measurement of this control network in each subsequent measurement session in order to check the stability of the control points.

Modern surveying solutions enable the measurement of the same structure in a much shorter period of time and with high accuracy, as declared by the manufacturers. Their use justifies a need for comparative surveys of the same structure with different techniques, and the repetition of these surveys in successive time intervals with reference to the results obtained from their initial survey.

\section{Further Research}

The results of the traditional surveying methods presented in this article are a reference point for the assessment of other surveying methods: ground-based radar interferometry and terrestrial laser scanning.

Ground-based radar interferometry is a modern surveying technique which has been used in the IBIS-L device by the Italian company IDS. The main purpose of this 
version of the IBIS system is surveying displacements of large-surface objects, such as landslides or earth dams. The declared by the manufacturer precision of measuring displacements at the level of $0.1 \mathrm{~mm}$ makes it possible to capture even the smallest movements of the retaining structures as well. On the other hand, terrestrial laser scanning is a dynamically-developing surveying technology which is finding more and more applications, including the study of displacements. According to the manufacturers, using the best reflectorless distance-meters, it is possible to measure the coordinates of point clouds with an accuracy of about 2-3 $\mathrm{mm}$. A large number of points allow for an accurate approximation of the surface of retaining walls, and repeated surveys make it possible to analyze changes in the shape and position of a given retaining structure.

The retaining walls presented in this article, during the initial session, was also subjected to surveys using terrestrial laser scanning technology and groundbased radar interferometry. The next stage of the research will be evaluating the results of these surveys by comparison with the results obtained by classical surveying methods.

\section{References}

[1] Dembicki E. (ed.): Fundamentowanie - projektowanie i wykonawstwo. Tom 2: Posadowienie budowli. Arkady, Warszawa 1988.

[2] EN 1997-1:2004. Eurocode 7: Geotechnical design - Part 1: General rules.

[3] Glinicki S.: Geotechnika budowlana. Część 1. Wydawnictwa Politechniki Białostockiej, Białystok 1990.

[4] Katalog inżyniera. Firmy i materiały budowlane, [on-line:] http://www. kataloginzyniera.pl/produkty/18248/Zerdz_systemu_TITAN_127_111. html [access: November 2013].

[5] Kulawik A.: Most nad dolinka w rejonie Lubnia. Nowoczesne Budownictwo Inżynieryjne, 4 (25), lipiec-sierpień 2009.

[6] Pisarczyk S.: Fundamentowanie dla inżynierów budownictwa wodnego. Oficyna Wydawnicza Politechniki Warszawskiej, Warszawa 2012.

[7] PN-B-03010:1983 Retaining walls - Static calculation and design.

[8] Titan Polska, [on-line:] http://www.titan.com.pl/geotechnika.html [access: November 2013].

[9] Wiłun Z.: Zarys geotechniki. Wydawnictwa Komunikacji i Łączności, Warszawa 2010. 